\title{
Sustainability Challenges in Managing End-of-Life Rolling Stocks
}

\author{
Sakdirat Kaewunruen ${ }^{1 *}$ and Cheul Kyu Lee ${ }^{2}$ \\ ${ }^{1}$ School of Engineering, The University of Birmingham, Birmingham, UK, ${ }^{2}$ Korea Railroad Research Institute, Seoul, \\ South Korea
}

Keywords: sustainability, recycle, recyclability, recovery, reuse, rolling stock, trains, railway systems

Sustainability has become one of the grand engineering challenges for transportation infrastructure developments. This paper addresses one of the grand challenges in transportation and transit systems (Kaewunruen et al., 2016), particularly for sustainably managing end-of-life rolling stocks or so-called "trains," which were the key outcomes derived from the 13th UIC Sustainability Conference (http://uic-environment.org/). The challenges and the roles of international standardization in order to substantially reduce waste generation through prevention, reduction, recycling, and reuse by 2030 were fully discussed with case studies evidenced from various countries around the world. The key point raised was that it is very critical to increase public awareness of the values of material recycling in order to enhance true sustainability and recyclability of rolling stocks.

Operations of railway systems have been the growth catalyst for economic and societal development all over the world for more than a couple of centuries. Many of rolling stocks have thus now reached the end of their lives. Throughout their service life, around 30\% of the whole cost

OPEN ACCESS

Edited by:

Samer Michel Madanat, University of California Berkeley, USA

Reviewed by: Ampol Karoonsoontawong, King Mongkut's University of Technology Thonburi, Thailand Julia Griswold, University of California Berkeley, USA

${ }^{*}$ Correspondence: Sakdirat Kaewunruen sakdirat@hotmail.com,

s.kaewunruen@bham.ac.uk

Specialty section:

This article was submitted to Transportation and Transit Systems, a section of the journal Frontiers in Built Environment

Received: 06 December 2016 Accepted: 23 January 2017 Published: 07 February 2017

Citation:

Kaewunruen S and Lee CK (2017) Sustainability Challenges in Managing End-of-Life Rolling Stocks.

Front. Built Environ. 3:10. doi: 10.3389/fbuil.2017.00010 is associated with the initial capital investment, $25 \%$ is for operating cost, and the remaining $45 \%$ is budgeted for maintenance (Office of Rail Regulation, 2011). This information implies that there were many of both cosmetic and structural changes (as part of operating and maintenance) in train bodies and/or rolling stock components over its life cycle due to retrofit, repair, reuse, or refurbishment. Note that the contemporary design of rolling stock does not allow modular assembly and therefore most existing rolling stocks would have experienced major modifications by the upgrades. Such the modifications would have changed material characteristics and properties of the parts or components. In fact, the modifications could be problematic toward the end-of-life stage of the rolling stocks, since they could undermine the ability to recycle and/or reuse the wastes. Nowadays, managing the end-of-life rolling stocks has been a crucial concern of rail authorities and asset owners since the public has raised expectation from them to improve the sustainability and minimize the environmental impacts of transportation and transit systems (Kaewunruen et al., 2016). In some countries (such as India), modern and innovative procurement processes for rolling stock acquisition have adopted sustainability issues as part of selection criteria for evaluating environment-friendly rolling stock design and manufacture. These sustainability criteria include matrices of recyclability of rolling stocks, low noise and vibration, high crashworthiness, lighter weight, energy efficiency, ride quality and passenger comfort, spacious body, modular design, momentum train driving pattern, low economic impact, low carbon footprint, etc. (Kaewunruen, 2016).

Collaborative efforts by rail authorities, universities and research institutions, train manufacturers, infrastructure managers, and asset owners have been carried out to establish mutual performance agreement using international standardization. The goal is to find the best solution to increase recyclability of rolling stock (e.g., $95 \%$ of mass) considering economic values and potential hazards to environment as well as human. An apparent activity is the development of a standard method for calculation of recyclability of rolling stocks (i.e., ISO TC269 WG4 Committee) that can be adopted by any new contracts. Figure 1 illustrates the concept of the method. This method is predominantly aimed for new rolling stocks at bidding stage with which each material data and its recovery rates can be associated. However, the method could be applied 


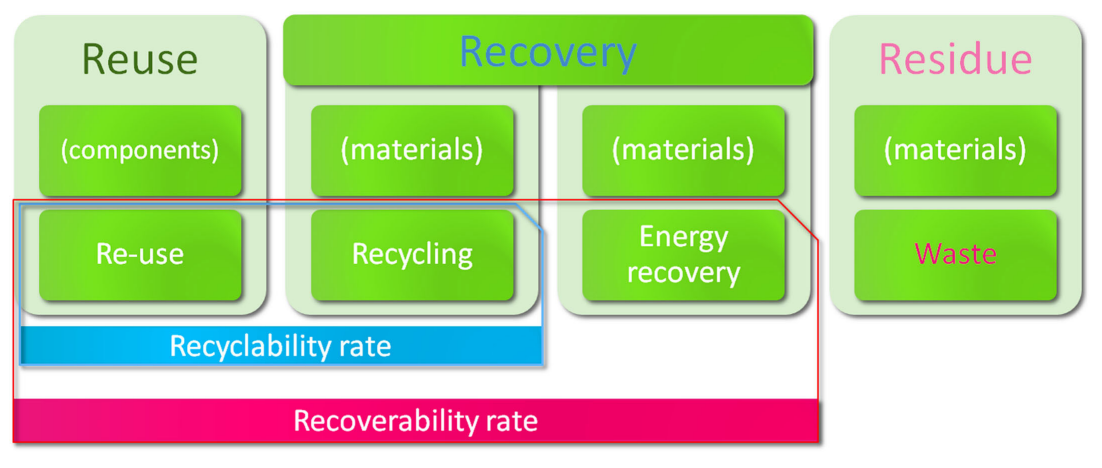

Design mass of rolling stock

FIGURE 1 | Schematic illustration of recovery, recycle, and reuse. Reuse means "any operation by which components of end-of-life rolling stock are used for the same purpose for which they were designed"; recycling is a method of "processing the waste materials for the original purpose or for other purposes, excluding processing as a means of generating energy"; and recovery applies to the concept of "processing the waste materials for the original purpose or for other purposes, including processing as a means of generating energy." The ratios of these fractions over the design mass have been adopted for the rate calculations (Kaewunruen, 2016).

to evaluate existing rolling stocks if pertinent data of materials can be obtained. It is very important to note that the calculation method is aimed for benchmarking purpose and it truly implies the total theoretical potential or possibility of materials that can be recycled. By contrast, it does not refer to the actual ability or capacity of recycling industry in any particular country to recycle the rolling stock or to reuse the material parts of the rolling stock. These attributes define the important scope and boundary of this standard, which is a challenge in efficiently managing the rolling stock wastes.

The balance among multi criteria such as benefit, economic cost, opportunity, and carbon footprint will need to be satisfied and the optimal can vary from place to place. These multi criteria have been a great challenge for developing countries when economic cost priority is more significant than environmental values and there is no incentive for recycling industry to further develop. A case study revealed that a small incentive has been introduced to the recycling plants in Japan. The end-of-life trains have been given to the recycling plant for free (Handa, 2016). However, such similar incentive cannot be observed elsewhere.

In many cases, the out-of-service trains or rolling stocks have been placed in wasteland or left in unused yards until further notice. This is because the high costs of recycling and the weak public interest discourage this recycling process that improves sustainability (Kaewunruen et al., 2015; Lee, 2016; Överstam, 2016). In addition, rolling stocks are exposed to various environmental conditions overtime and they might possess toxics and biological hazards. A clear example is the asbestos that can be found inside the train body (Garnier de Falletans, 2016). The hazard risk and the cost of treatments can also undermine or discourage the recycling of the aged cluster of rolling stocks. These factors will altogether decrease the public support for the waste management scenario.

Another important key challenge is the lack of information on material recycle and recovery capabilities. Today material data may not necessarily reflect the material characteristics or properties used in the past. The use of irrelevant or trivial material data could mislead the rate calculation results. As such, we need to encourage more research into recycling of both existing materials (e.g., steel, rubber, glass) and future materials (e.g., composites), as well as to promote open-access publications in this field to railway sector.

In summary, we would like to quote: "Considering recyclability of rolling stock from the design stage with a standardized guideline contributes to improve its environmental performance and economic values and further sustainable development of railway industry. The rail sector needs to implement sustainable procurement with life cycle perspective. Integration of eco-design into manufacturing rolling stock reinforces railway industry solid position among transportation modes. With $10 \%$ improvement of recyclability at European rail sector, economic benefit will be expected by at least 170 Million Euros per year" (UIC International Union of Railway, 2016).

\section{AUTHOR CONTRIBUTIONS}

Both authors wrote and contributed their experience and industry outcome to the manuscript.

\section{ACKNOWLEDGMENTS}

The authors appreciate valuable comments and discussions from committee members during the ISO TC269 WG4 meetings. The authors also are sincerely grateful to European Commission for the financial sponsorship of the H2020-MSCA-RISE Project No. 691135 "RISEN: Rail Infrastructure Systems Engineering Network," which enables a global research network that tackles the grand challenge in railway infrastructure resilience and advanced sensing under extreme environments (http://www. risen2rail.eu). 


\section{REFERENCES}

Garnier de Falletans, T. (2016). "Levers for recyclable trains," in The 13th UIC Sustainability Conference, 12-14 October 2016 (Vienna, Austria).

Handa, K. (2016). "Features of rolling stock recycling technology in Japan," in The 13th UIC Sustainability Conference, 12-14 October 2016 (Vienna, Austria).

Kaewunruen, S. (2016). "Recent progress and challenges in recyclability of rolling stock," in The 13th UIC Sustainability Conference, 12-14 October 2016 (Vienna, Austria).

Kaewunruen, S., Sussman, J. M., and Einstein, H. H. (2015). Strategic framework to achieve carbon-efficient construction and maintenance of railway infrastructure systems. Front. Environ. Sci. 3:6. doi:10.3389/fenvs.2015.00006

Kaewunruen, S., Sussman, J. M., and Matsumoto, A. (2016). Grand challenges in transportation and transit systems. Front. Built Environ. 2:4. doi:10.3389/ fbuil.2016.00004

Lee, C. K. (2016). "Standardization in progress for the recyclability of rolling stock," in The 13th UIC Sustainability Conference, 12-14 October 2016 (Vienna, Austria).

Office of Rail Regulation. (2011). "Rail value for money study: rolling stock whole life cost," in Arup's Final Report (London, UK). Available at: http://orr.gov. uk/_data/assets/pdf_file/0011/2711/rvfm-arup-rolling-stock-mar2011.pdf
Överstam, U. (2016). "Applying eco-design guidelines when designing rolling stock," in The 13th UIC Sustainability Conference, 12-14 October 2016 (Vienna, Austria).

UIC International Union of Railway. (2016). Recyclability of Rolling Stock Workshop (Moderated by Kaewunruen). Available at: http://uic-environment.org/ workshops\#Recyclability-of-Rolling-stock

Conflict of Interest Statement: The authors declare that the research was conducted in the absence of any commercial or financial relationships that could be construed as a potential conflict of interest.

The reviewer (JG) and handling Editor declared their shared affiliation, and the handling Editor states that the process nevertheless met the standards of a fair and objective review.

Copyright (c) 2017 Kaewunruen and Lee. This is an open-access article distributed under the terms of the Creative Commons Attribution License (CC BY). The use, distribution or reproduction in other forums is permitted, provided the original author(s) or licensor are credited and that the original publication in this journal is cited, in accordance with accepted academic practice. No use, distribution or reproduction is permitted which does not comply with these terms. 